\title{
Error Modeling Radar Rainfall Estimation Through Incorporating Rain Gauge Data Over Upper Blue Nile Basin, Ethiopia
}

\author{
Megbar W. Birhan, U. Jaya Prakash Raju and Samuel T. Kenea
}

\begin{abstract}
Accurate and precise measurements of rainfall from weather radar reflectivity data is essential to supplement the limited characterization of spatial and temporal measurements provided by insufficient network and density of rain gauges. While weather radar has high spatial and temporal resolution, it contaminated with various sources of errors due to the conversion of reflectivity to rain rate and the projectile rainfall motion. Error modeling improvement with the application of projectile rainfall motion correction is essential to improve the radar data. However, stile is not well documented for over the world as well as Ethiopia. Therefore, the aim of this study was to generate an error model for weather radar rainfall estimation by incorporating gauge rainfall data over upper Blue Nile basin, Ethiopia. Projectile rainfall motion correction is considered on the data of reflectivity and rain rate to determine empirical error model parameter values. The model parameter values are found, multiplicative factor (a) was 55, the exponent factor (b) was 1.12, standard deviation of proportional error was 0.08 and standard deviation of random error was 0.07 . The value of the total error varied from -0.45 to $1.16 \mathrm{~mm}$ and the domain of proportional error was greater than random error. After applying the projectile rainfall motion correction, the total error is reduced by $12 \%$. In general, the assumption of projectile method is quite useful for improving the radar data over upper Blue Nile basin in Ethiopia as well as over the world. Hence, we wish to extend this method for other regions.
\end{abstract}

Index Terms-Error modeling, gauge, rainfall, reflectivity, weather radar.

\section{INTRODUCTION}

A $\mathrm{N}$ accurate and precise measurement of rainfall is a fundamental requirement for improving the prediction of weather systems and climate change [1]. Standard rain gauges provide relatively accurate measurements at a single location [2]. However, the number of standard gauge stations is irregular and sparsely distributed in developing countries. For example African Climate Policy center (ACPC) assessment report indicates that the spatial coverage of African climate stations is in the order of one station per $27,347 \mathrm{~km}^{2}$. In Ethiopia, there are 319 meteorological gauging stations for the entire area of $1,120,000 \mathrm{~km}^{2}$ (one station per $3,511 \mathrm{~km}^{2}$ ).

Manuscript received January 11, 2019; accepted July 10, 2019.

M.W. Birhan and U.J.P. Raju are with the Washera Geospace and Radar Science Laboratory, Department of Physics, Science College, Bahir Dar University, Bahir Dar, Ethiopia. E-mail: megbar.radiation05egmail. com

Climate Research Division, National Institute of Meteorological Sciences (NIMS), Jeju-do, Republic of Korea.

The authors are thankful to Blue Nile Water Institute for the financial support and Physics Department, Bahir Dar University for the material support.
It was reported by National Meteorological Services Agency (NMSA). It is less than the World Meteorological Organization (WMO) standards, that is one station per $500 \mathrm{~km}^{2}$ for high population regions. Upper Blue Nile Basin (UBNB) is similar with station in the rest of Ethiopia regions that have high rainfall variability due to the mountainous terrain and several converging air masses. Therefore, in addition to gauge observation, alternative technologies such as satellites and weather radar are useful to represent better spatial and temporal coverage. Satellites are expensive regarding to cost compared to the radar and it offers a global solution but their resolution and accuracy is limited compared to weather radars [3]. The estimation of quality rainfall data from single radar provides quite useful and it gives important information for flood prediction and it is expected by hydrologists [4], [5], [6], [7].

Operating weather radar in a developing country poses unique challenges to understand storm predictions. Developing countries has also fallen behind in terms of new technologies and ways to measure radar rainfall estimates and new radar operation techniques [8], [9] as Ethiopia is still stuck with rain gauge measurements. The UBNB, Ethiopia is an extremely important part of the country due to the availability of precipitations, optimum temperature, and surface water and underground water. At this region, the population density is high [10]. Therefore, in addition to gauge measurement, we need highly accurate and reliable weather radar rainfall data within this area. Recently one C-band dual polarized the first weather radar is installed within UBNB in 2016 by the National Meteorological Institute of Ethiopia at Washera to model rainfall over some vulnerable parts of the research domain. This weather radar has its own specifications [11].

Thus, we had got this chance. We used weather radar rainfall data for the first time from June 22 to July 14, 2016. As we consider a short period of data in the study, due to the power supply fluctuation, lack of skillful persons on this new technology. Weather radar has the highest potential to measure rainfall with required spatial and temporal resolution. But, it provided only indirect measurements that leads many sources of errors [12], [13] such as the additive error which is random error, multiplicative error which is the proportional error associated with $\mathrm{Z}$ and $\mathrm{R}$, and physical error, which is generated due to projectile rainfall motion, beam blockage, clutter and overshoot of the signal [14], [15]. Beam blockage, clutter and overshoot of the signal are not our interest; because before installation of weather radar, we had taken deep study 
for prefer good sites to resolve those challenges.

Weather radar rainfall error modeling was well presented in the previous reports [16], [17], [18], [19], [20]. Hardware sources of errors are related to electronics stability, antenna accuracy, and signal processing accuracy studied by [21]. Nonmeteorological errors are results of electromagnetic interference with the sun and beam blockage due to topography error is addressed by [13], [22], [23]. In the case of UBNB in Ethiopia, spatiotemporal variability of rainfall using weather radar Z-R relation model is investigated by [11]; however, they have not considered the projectile rainfall motion errors. From the scholars [18], [19] extracts errors in a better way using least square and likelihood methods with compared to other scholars. Even thought, they have not been verified on the projectile rainfall motion errors. They are limited on proportional and random error terms.

The projectile rainfall motion is an additional component of physical error which is defined as the error due to horizontal projectile of target droplet at the ground during the vertical free fall motion. Weather radar observes rain droplets at some cloud level. These rain droplets may not be straight to the ground gauge stations due to wind shear. Therefore, an error modeling improvement with the application of projectile rainfall motion correction is essential for meteorologists and hydrologists to extract accurate and precise rainfall data from weather radar to provide accurate predictions. There was no previous study to consider projectile rainfall motion errors in the world as well as UBNB, Ethiopia. Therefore, to fill in this gap, this paper is aimed as the error modeling radar rainfall estimation through incorporating rain gauge data within mountainous topography and sub-humid climates of Ethiopia by applied the projectile rainfall motion correction.

\section{DATA, Methods AND Site DESCRIPTION}

\section{A. Description of the study area}

The UBNB covers a large area about $176,000 \mathrm{~km}^{2}$; and extends from $7^{\circ} 40^{\prime}$ to $12^{\circ} 5^{\circ} \mathrm{N}$ and $34^{\circ} 25^{\prime}$ to $39^{\circ} 49^{\prime} \mathrm{E}$ which is located in Ethiopian highlands (Fig. 1). The river extends from Lake Tana to Sudan. The annual precipitation increases from northeast to southwest [10]. Since the UBNB has the share of the total Nile flow, it is the economic mainstay of downstream countries (i.e. Sudan and Egypt) [24], [25]. Moreover, the Ethiopian highlands are highly populated and have high water demands for irrigation and domestic uses of their own. The topography of UBN is very complex with elevation ranging from $500 \mathrm{~m}$ to $4160 \mathrm{~m}$ in the upper parts of the basin [25]. Due to the topographic variations, rainfall spatial and temporal distribution variability is high with a limited elevation range. The mean annual rainfall and potential evapotranspiration of UBNB are estimated to be in the ranges of 1200 to $1600 \mathrm{~mm}$ and 1000 to $1800 \mathrm{~mm}$, respectively [24], [26]. Hence, accurate and prices rainfall data with a required resolution from weather radar reflectivity data is essential to study the rainfall variability on the water tower and high population UBNB region. The rain gauge and weather radar station distributions on the map to include in this study area were provided in Fig. 1.


Fig. 1: Location map of UBNB from Ethiopia.

\section{B. Data Availability}

The hourly and daily reflectivity, height and directional angle data is obtained from UBNB weather radar from June 22 to July 14,2016 . The corresponding gauge for hourly and daily rainfall and wind data is obtained from National Meteorology Agency from seven different stations (Bahir Dar, Dangla, Motta, Debre Markos, Adiet, Debre Tabor and Gonder) located on UBNB, Ethiopia from June 22 to July 14, 2016. We selected the seven stations due to the availability of hourly and daily rainfall data and their proximity to the radar site over UBNB (see Fig. 1). The third daily precipitation and wind data is obtained from European Center Medium-range Weather Forecast (ECMWF) reanalysis dataset (ERA-Interim) from June 22 to July 14, 2016. The current updating grid horizontal resolution is 0.1250 .125 degree and daily time scale. The data is analyzed using MATLAB and IRIS software.

\section{Methodology}

We have followed three steps in Fig. 2 to model rain rate from the weather radar reflectivity data: 1) The projective rainfall motion is applied to estimate reflectivity ( $\mathrm{Zp})$ at horizontal distance $\mathrm{p}$ and height $\mathrm{h}$ of a particular rain gauge. In addition, conventional reflectivity $\mathrm{Zc}$ (perpendicular to the particular gauge) at height $\mathrm{h}$ from the rain gauge location is recorded from the weather radar; 2) The least square regression method is applied on $\mathrm{Z}$ and $\mathrm{R}$ data to find the multiplication factor $a$ and exponential factor $b$. These relationships have been conducted for both projected reflectivity $\mathrm{Zp}$ and conventional reflectivity Zc; 3) Finally, proportional and random errors are determined by applying likelihood function method.

1) Projective Rainfall Motion Correction: To determine the atmospheric contact points of the radar above the ground, we used the projectile rainfall motion assumptions. Wind, height and directional angle data are very important to calculate longitudinal (horizontal) distance using the projectile equation of motion. The distance $\mathrm{P}$ is calculated by:

$$
P(\varphi(h))=\frac{v^{2} \sin 2 \varphi}{2 g}
$$

where $P$ is the horizontal distance in meter, $h$ is the altitude in meter, $v$ is the wind speed meter per second, $\varphi$ is the 


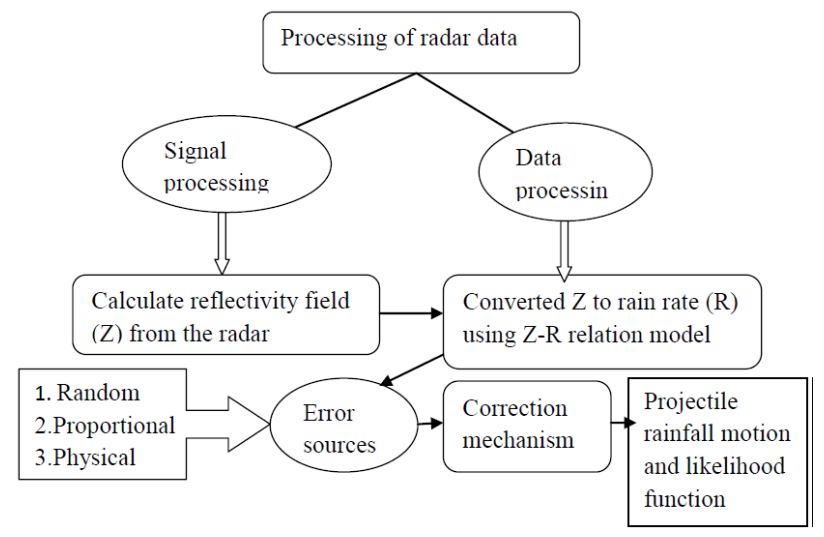

Fig. 2: Three steps to model rain rate from the weather radar reflectivity data.

directional angle between the horizontal and the trajectory path in degree and $g$ is the gravitational acceleration in meter per second square.

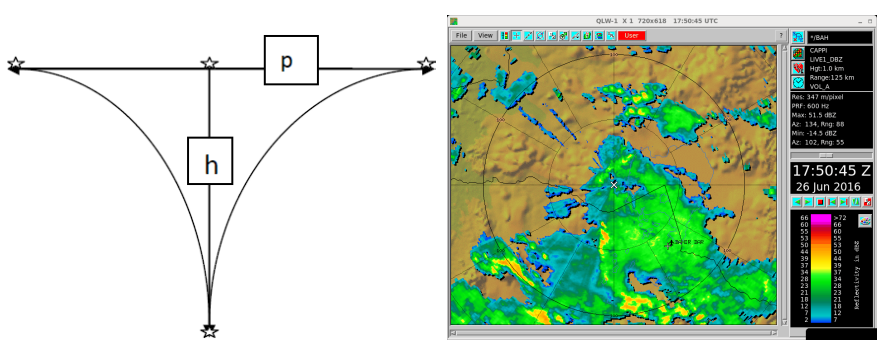

Fig. 3: The trajectory path of rainfall motion from some altitude to the ground station.

Radar is an areal rainfall reflectivity measurement technology; which is observed rainfall at some altitudes. We are considering three important points which are the left, the middle and the right stars at some altitude from the ground, and particular gauge stations located at the bottom stares as shown the left panel of Fig. 3. Variable $R$ is measured from the gauge direct observation and compared to weather radar Z-R relation error modeling products, assuming three opposing directional angle and wind conditions. 1) First, daily wind is assumed to be zero so that rain would fall directly vertically to the gauge (from the middle star at some altitude $h$ to the bottom star at the ground particular gauge station). The reflectivity, Zc, from the radar is collected at the same coordinates as the rain gauge station. 2) Next, we assumed a daily westerly wind generated projectile motion following the westerly path (see Fig. 3). Thus, we collected reflectivity, $Z p$ data from the radar westerly distance ' $p$ ' from the normal vertical distance $h$ (considering the left top star in Fig. 3). 3) Finally, we assumed an easterly wind causing rain to fall along a projectile path to the right of the vertical (Fig. 3). Weather radar reflectivity, $\mathrm{Zp}$, is obtained from the radar at an altitude $h$ from an easterly position $p$ distance from the normal vertical line. Observed rain gauge measurements are obtained from an individual ground gauge station.

2) Developing Z-R Relation: The Z-R relationship is an empirical with power equation model [27], [28], [29]. To determine multiplicative factor ' $a$ ' and exponential factor ' $b$ ' from Z-R relation power empirical equation, least square method is followed with the data of $\mathrm{Z}$ and $\mathrm{R}$. The power mathematical equation is described as:

$$
Z=a R^{b} \Rightarrow R=(Z / a)^{1 / b}
$$

where $Z$ is the reflectivity data obtained from weather radar with and without projectile rainfall motion assumption (Zp and $\mathrm{Zc}$ ). Variable $R$ is the rainfall rate data obtained from rain gauge stations around UBNB. We applied natural logarithmic rule both sides in (2) to obtain

$$
\ln Z=\ln a+b \ln R
$$

If we substitute $\ln Z$ as $y, \ln a$ as $m$ and $\ln R$ as $x$, we obtain the following simple linear equation

$$
y=m+b x
$$

where $a$ is the exponential value of $m$ (the $y$ intercept) and $b$ is the slope of a function which is calculated by applying the least square method.

3) Proportional and Random Errors Modeling: The last approach in this study was determining proportional and random errors by applying likelihood function method. Then, we generated new empirical Z-R relation error model

$$
R=(Z / a)^{1 / b}+(Z / a)^{1 / b} \varepsilon_{1}+\varepsilon_{2}
$$

Assuming normally distributed error $\varepsilon_{1}$ is a proportional error term which is the mean value of the measured rain rate $\mathrm{R}$ from (2) after determining ' $\mathrm{a}$ ' and ' $\mathrm{b}$ ' parameter values. Parameter $\varepsilon_{2}$ is a purely random error which is standard deviation of the measurement rain rate $R$. The term $(Z / a)^{1 / b} \varepsilon_{1}$ represents the error component that is proportional to the magnitude of $Z$ and $R$. Based on the central limit theorem, the sum of all errors tends to Gaussian distribution errors [16]. Recent studies [16], [18], [19] indicated that, weather radar error may depend on the magnitude of $R$ and $Z$. In order to filter out the dependency, proportional error terms are essential. The total errors of the measurement were clearly stated by (6).

$$
\begin{aligned}
\varepsilon & =(Z / a)^{1 / b} \varepsilon_{1}+\varepsilon_{2}=R_{i}-\left(Z_{i} / a\right)^{1 / b} \\
\sigma_{1} & =\operatorname{std}\left[(Z / a)^{1 / b} \varepsilon_{1}\right] \\
\sigma & =\sqrt{\sigma_{1}^{2}+\varepsilon_{2}^{2}}
\end{aligned}
$$

The term $\sigma_{1}$ in (7) is standard deviation of the proportional error. The standard deviation of the total error is the component of both error terms, which is calculated by (8). Substituting the total standard deviation from both errors into probability density function produced the likelihood function as shown in (9) after some algebraic manipulation [30], [31], [32].

$$
\varepsilon=\left(x_{1}, \ldots, x_{n} \mid 0, \sigma^{2}\right)=\left(\frac{1}{2 \pi \sigma^{2}}\right)^{1 / n} \exp \left(-\frac{\sum_{i=1}^{n} x_{i}}{2 \sigma^{2}}\right)
$$

where $x_{i}=R_{i}-\left(Z_{i} / a\right)^{1 / b}$. The application of natural logarithm on both sides of (9) yields

$$
L f=-\frac{n}{2}(\ln 2 \pi)-\frac{n}{2} \sigma^{2}-\frac{1}{2}\left(\frac{\sum_{i=1}^{n} x_{i}}{\sigma^{2}}\right)
$$


where $L f$ is a likelihood function and the term $x_{i}$ refers to the total error associated with Z-R relation. The model parameters $a, b, \sigma$ are estimated simultaneously using the maximum likelihood method from (10). The parameter values which are maximized the likelihood function that satisfied our error model requirements over the study domain. From a practical viewpoint, the method of maximum likelihood has proven robust and reliable in hydrologic applications [30], [33]. After determined those four parameters, finally we calculated rain rates from reflectivity. We also estimated the correlation coefficient between rainfall from the gauge direct observation and from the weather radar Z-R relation error model. The biased ratio and mean relative error is calculated by

$$
\begin{aligned}
\text { Bias } & =\frac{\sum_{i=1}^{n} G_{i}}{\sum_{i=1}^{n} R_{i}} \\
M R E & =\frac{\sum_{i=1}^{n}\left(R_{i}-E C_{i}\right)}{\sum_{i=1}^{n} E C_{i}}
\end{aligned}
$$

where $M R E$ is mean relative error, $G_{i}$ is represented gauge observation, $R$ is estimated Z-R relation model rainfall data from the radar and EC is ECMWF ERA-interim rainfall data.

\section{RESUlTS AND DiscUSSIONS}

Weather radar rainfall measurements are necessary to capture high spatial resolutions of rainfall data after the error model parameters are determined. We estimated rainfall rate from weather radar rainfall reflectivity and compared these values against the gauge rainfall observation across Ethiopian highlands.

\section{A. Z-R Relation Parameter Values}

The parameters $a, b, \sigma_{1}^{2}, \varepsilon_{1}^{2}$ for all selected stations are determined using least square and likelihood function method by applying projectile rainfall motion correction as described in Section II-C. Debre Markos and Motta found that similar parameter values, so considered Motta station parameter values. Similarly, we observed at Adiet and Dangla stations nearly similar parameter values. Therefore, we took Dangla station parameter values. After applying projectile rainfall motion, Debre Tabor and Gonder stations have similar parameter values. Hence, we took Gonder station. The parameters of those stations were clearly shown in Table I. Parameter values before the application of projectile motion correction were $a=50, b=0.89, \sigma_{1}=0.30$ and $\varepsilon_{2}=-0.08$. While after the application of projectile motion correction is $a=55$, $b=1.12, \sigma_{1}=0.08$ and $\varepsilon_{2}=0.07$ that satisfied our model requirements, since those values which are maximized the likelihood function.

\section{B. Comparison of Gauge and Weather Radar With and With- out Applying Projectile Motion}

The range of daily wind speed at Bahir dar, Debre Markos, Adiet, Debre Tabor and Dangla stations are varied from 0.12 to $2.73 \mathrm{~m} / \mathrm{s}$. However, at Gonder gauge station the wind speed was slightly higher than the rest of the stations, which were
TABLE I: Estimation of model parameters for Bahir Dar, Dangla, Motta and Gonder stations.

\begin{tabular}{c||c|c|c|c}
\hline Station & $a$ & $b$ & $\sigma_{1}^{2}$ & $\varepsilon_{2}^{2}$ \\
\hline \hline Bahir Dar & 30 & 0.65 & 0.010 & 0.020 \\
\hline Dangla & 55 & 1.12 & 0.007 & 009 \\
\hline Motta & 53 & 0.98 & 0.008 & 0.009 \\
\hline Gonder & 50 & 1.10 & 0.016 & 0.074 \\
\hline
\end{tabular}

TABLE II: The correlation between radar Z-R relation model before and after the application of projectile rainfall motion assumption and the gauge observation from June 22 to July 14, 2016.

\begin{tabular}{c||c|c}
\hline \multirow{2}{*}{ Stations } & \multicolumn{2}{c}{ The correlation between gauge and weather radar } \\
\cline { 2 - 3 } & $\begin{array}{c}\text { Before projectile } \\
\text { motion correction }\end{array}$ & $\begin{array}{c}\text { After projectile } \\
\text { motion correction }\end{array}$ \\
\hline \hline Bahir Dar & 0.933 & 0.997 \\
\hline Debre Markos & 0.917 & 0.995 \\
\hline Debre Tabor & 0.846 & 0.977 \\
\hline Adet & 0.889 & 0.997 \\
\hline Gonder & 0.308 & 0.933 \\
\hline Dangla & 0.973 & 0.994 \\
\hline
\end{tabular}

within range of 2.10 to $5.31 \mathrm{~m} / \mathrm{s}$. The wind was a dominant factor of the study period for large deviation of rainfall from the gauge and Z-R relation error model from the radar. This was clearly observed in the temporal variability of rainfall for Dangla and Gonder gauge stations (see Fig. 4).

The green lines on Fig. 4 represents $R$ is obtained from gauge direct observation while black and red lines represent $R$ is obtained from Z-R relation empirical error model before and after applying projectile rainfall motion correction, respectively. The correlation between measured rainfall from rain gauge and estimated rain from $\mathrm{Z}-\mathrm{R}$ relation model before and after in the application of projectile motion is provided in Table II.

The correlation between gauge observation and Z-R relation error model rainfall data at Bahir Dar, Debre Markos, Adet, Debre Tabor and Dangla is nearly the same before and after we applied the projectile motion (see Table II). At Dangla station, the correlation between gauge and Z-R relation model output before and after the application of projectile motion was 0.97 and 0.99 , respectively. The great difference between gauge and $\mathrm{Z}-\mathrm{R}$ relation error model before and after the application of projectile motion is observed at Gonder station.

The variation of rainfall data taken from Dangla station from the gauge direct measurements and Z-R relation error model from the weather radar with and without projectile motion assumption was minimum as shown in Fig. 4a. Because, the range of the $P$ value at an altitude of $h$ in this station is varied from 6.72 to 104.45 meter with an average of 21.381 meter, this minimum horizontal projectile $P$ distance is occurred due to the minimum wind speed on the station.

Large uncertainty and high variability between gauge and weather radar error model data without projectile rainfall motion correction is observed at Gonder station, we can see the bottom panel of Fig. 4. This variation might be occurred as 


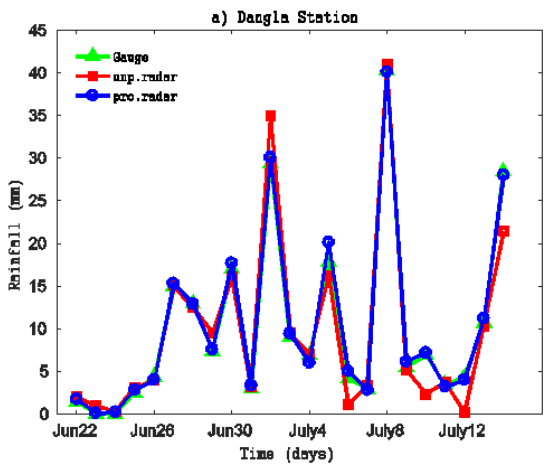

(a) Dangla station

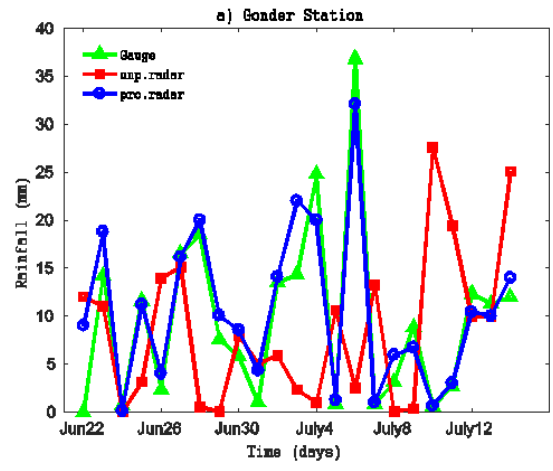

(b) Gonder station

Fig. 4: Comparisons of rainfall observation at Dangla and Gonder gauge station with and without projectile rainfall motion correction on the weather radar Z-R relation model rainfall observation from June 22 to July 14, 2016.

TABLE III: The range of the projectile zonal distance $P$.

\begin{tabular}{c||c|c|c}
\multicolumn{1}{c||}{\multirow{2}{*}{ Stations }} & \multicolumn{3}{c}{ The $P$ value in meter } \\
\cline { 2 - 4 } & $P_{\max }$ & $P_{\min }$ & $P_{\text {ave }}$ \\
\hline \hline Bahir Dar & 114.92 & 5.43 & 32.26 \\
\hline Debre Markos & 120.11 & 11.09 & 82.71 \\
\hline Debre Tabor & 1211.91 & 352.66 & 512.08 \\
\hline Adet & 1098.73 & 278.84 & 420.90 \\
\hline Gonder & 1782.42 & 922.78 & 1302.43 \\
\hline Dangla & 104.45 & 6.72 & 21.38 \\
\hline
\end{tabular}

the result of topography variability and strong wind shear as mentioned in the above. Therefore, the maximum wind speed at this station led to a large range value of $P$ which is found to be 178.42 meter horizontally, the rain that falls from some cloud level to the ground. The largest difference in correlation before and after projectile motion correction was 0.308 and 0.933 , respectively. The correlation at this station became poor because of the higher projectile motion (the largest $P$ value) due to strong wind shear (see Table III).

\section{Estimation of Different Types of Errors Before and After the Application of Projectile Rainfall Motion Correction}

In this study, we demonstrate the proportional error, purely random error and the total errors between the rainfall from the gauge direct observation and estimated rainfall from the weather radar Z-R relation error model.

Proportional error is depends on the magnitude of $\mathrm{R}$ and $\mathrm{Z}$ (see Fig. 5 in part 'd' and ' $\mathrm{a}$ '), whereas random error remains independent (see Fig. 5 in part 'e' and 'b'). It is agreed with [18], [19] findings. Before the application of projectile rainfall motion correction, proportional error is varied from -0.60 to $3.30 \mathrm{~mm}$ with an average of $0.30 \mathrm{~mm}$. The value of random error is varied from -1.70 to $0.50 \mathrm{~mm}$ with an average of $-0.08 \mathrm{~mm}$. The range of proportional error was greater than the random error. The difference between rainfall that is obtained from Z-R relation model and gauge direct observations is referred to as the total error. It varied from 0.90 to $2.30 \mathrm{~mm}$ with an average of $0.24 \mathrm{~mm}$ refer the left; top, middle and bottom panels of Fig. 5, respectively. The weather radar error model is studied by [18], [19] and they found that proportional error is varied from -3.70 to $3.90 \mathrm{~mm}$ and random error is varied from -1.50 to $1.00 \mathrm{~mm}$. The range of the total error is varied from -3.70 to $3.90 \mathrm{~mm}$. Hence, our error results before the application of projectile motion assumption were nearly similar with previous reports [18], [19]. After the application of projectile rainfall motion correction, the range of proportional error is varied from -0.60 to $1.44 \mathrm{~mm}$ with an average of $0.08 \mathrm{~mm}$. The value of random error is varied from -0.74 to $0.40 \mathrm{~mm}$ with an average of $0.07 \mathrm{~mm}$. The range of the total error is varied from -0.45 to $1.16 \mathrm{~mm}$ with an average of $0.12 \mathrm{~mm}$ as shown on the right; top, middle and bottom panel of Fig. 5, respectively. Hence, after we applied the projectile rainfall motion correction, the error was slightly less than the previous reports [18], [19]. Our error results before and after the application of projectile rainfall motion assumption are also inconsistent. Hence, the proportional error from $0.30 \mathrm{~mm}$ reduced to $0.08 \mathrm{~mm}$ by $22 \%$. While, random error from -0.08 $\mathrm{mm}$ reduced to $0.07 \mathrm{~mm}$ by $1 \%$ and the total error is reduced by $12 \%$. Therefore, the application of projectile rainfall motion assumptions is quite useful to estimate error model parameter components in addition to the other suggested methods.

\section{Estimation of Rainfall Bias Between Weather Radar After Applied Projectile Rainfall Motion Correction and Gauge Measurements}

At Bahir Dar station on June 24, 2016 and at Dangla station on June 23 and 24, 2016 the bias graph shows discontinuity, because with this days zero rainfall observation is recorded in the gauges (see Fig. 6).

The value of the bias at Bahir Dar station is varied from 0 to 1 with an average of 0.91 . At Gonder station, the value is varied from 0 to 8 with an average of 1.2, whereas, at Dangla station, the value is varied from 0 to 1 , with an average of 0.82 . On day 24, 2016 the bias shows the highest variation among the three stations. In this finding, the range of the bias is slightly less than the previous reports [17], [19]. For example [19] found that the range of the bias is varied from 0.98 to $1.02 \mathrm{~mm}$. 

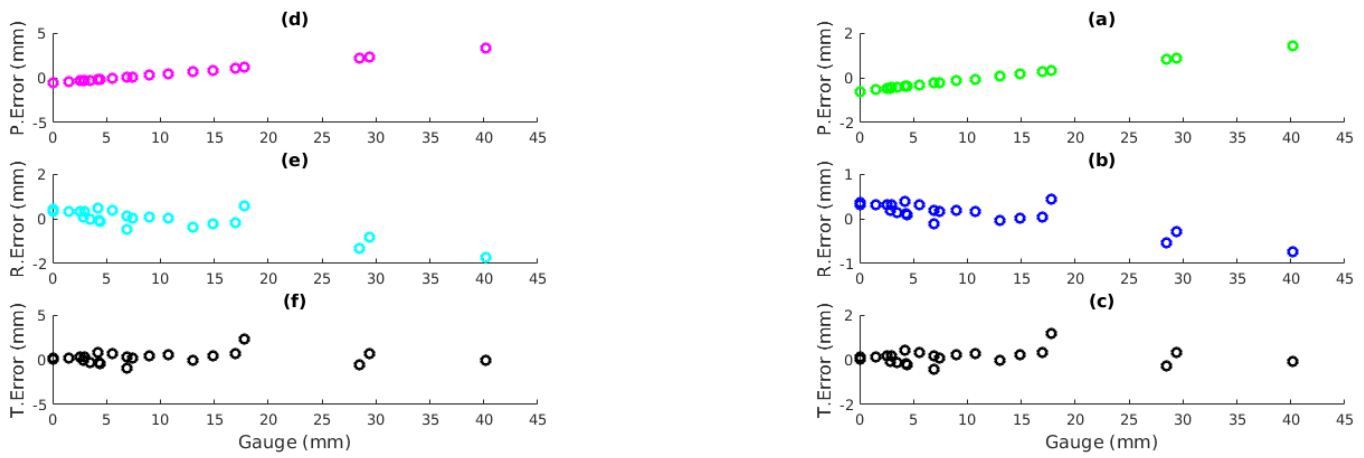

Fig. 5: Proportion, random and the total errors before and after the application of projectile rainfall motion correction.
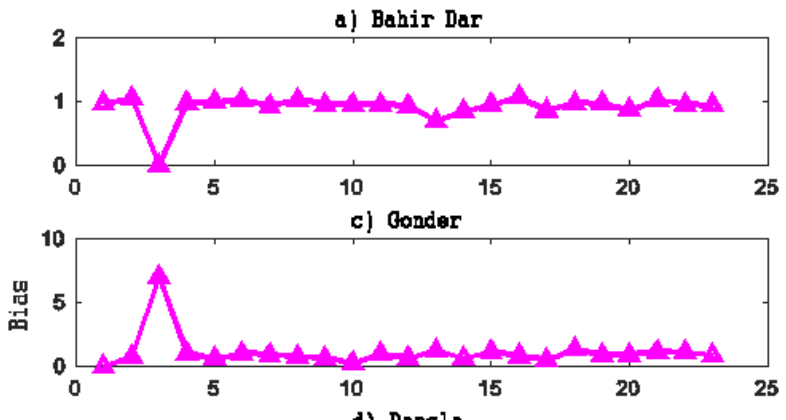

d) Dangla

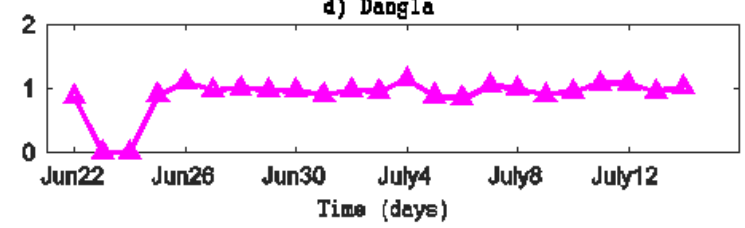

Fig. 6: The biases of the three stations between weather radar rainfall observation after we applied projectile correction and gauge observations from June 22 to July 14, 2016.

\section{E. Weather Radar Rainfall Observation with the Total Error and After Removing the Total Error}

The comparison of rainfall observation from weather radar error model with the total error and after we removed the errors at Bahir Dar, Gonder and Dangla stations (Fig. 7).

The red line of Fig. 7 indicates the weather radar rainfall observation with error, whereas the black line indicates the weather radar rainfall observation after removing the error. So, the magnitude of weather radar rainfall observation with error was greater than without error. Since, rainfall is estimated from the weather radar Z-R relation model is contaminated with various sources of errors. After removing such errors, we obtained the true value of rainfall information with respect to the gauge measurement. At Bahir Dar gauge station, the range of rainfall with error is varied from 0.2 to $0.5 \mathrm{~mm} / \mathrm{h}$ and without error is varied from 0 to $0.35 \mathrm{~mm} / \mathrm{h}$. In Gonder gauge station weather radar rainfall rate estimation with error is varied from 0.3 to $1.5 \mathrm{~mm} / \mathrm{h}$ and without error is varied from 0 to $0.8 \mathrm{~mm} / \mathrm{h}$. At Dangla gauge station with error is varied from $0.2 \mathrm{~mm} / \mathrm{h}$ to $0.9 \mathrm{~mm} / \mathrm{h}$ and without error is varied
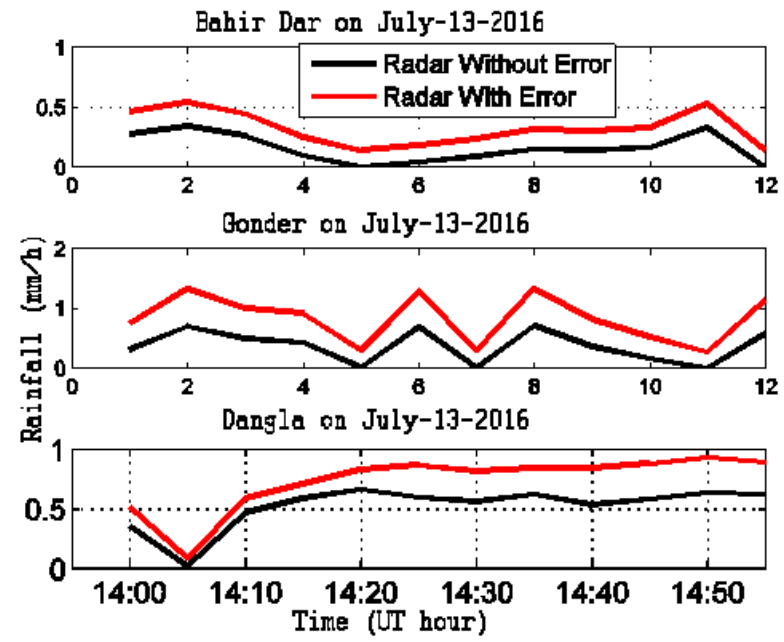

Fig. 7: Weather radar hourly rainfall variation with error and without error.

from 0 to $0.6 \mathrm{~mm} / \mathrm{h}$. The maximum deviation is occurred at Gonder gauge station.

\section{F. The Performance of ECMWF ERA-Interim Data Against $Z-R$ Relation Model Precipitation Data From the Radar After Removing the Total Error}

The top-left panel of Fig. 8 depicts the spatial distributions of rainfall from the radar Z-R relation model after projectile rainfall motion error correction is applied using the IRIS software. While, the top-right panel is depicted from ECMWF ERA-interim precipitation data using MATLAB software on 07 July 2016. The radar is installed on 11.10 latitude and 37.40 longitudes. It scans the precipitation in the radius of $250 \mathrm{~km}$ in constant amplitude plane position indicator products (CAPPI) and rain $\mathrm{N}$ products. Therefore, it covers $8.8 \mathrm{~N}$ to $13.00 \mathrm{~N}$ and $34.4 \mathrm{E}$ to $39.2 \mathrm{E}$ degrees. In this domain, the maximum amount of rainfall is found in the southern and eastern parts of the radar with an estimated value of $26 \mathrm{~mm}$ from the Z-R relation model. Similarly, from ECMWF data, the maximum amount of rainfall is found in the southern and eastern parts of UBNB within the radar domain an estimated 

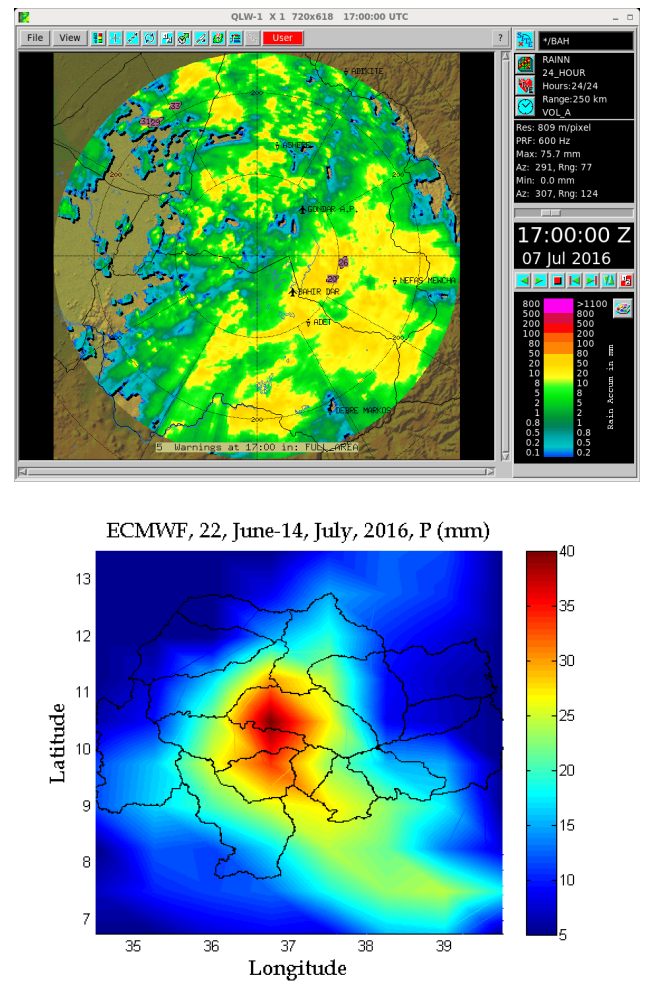
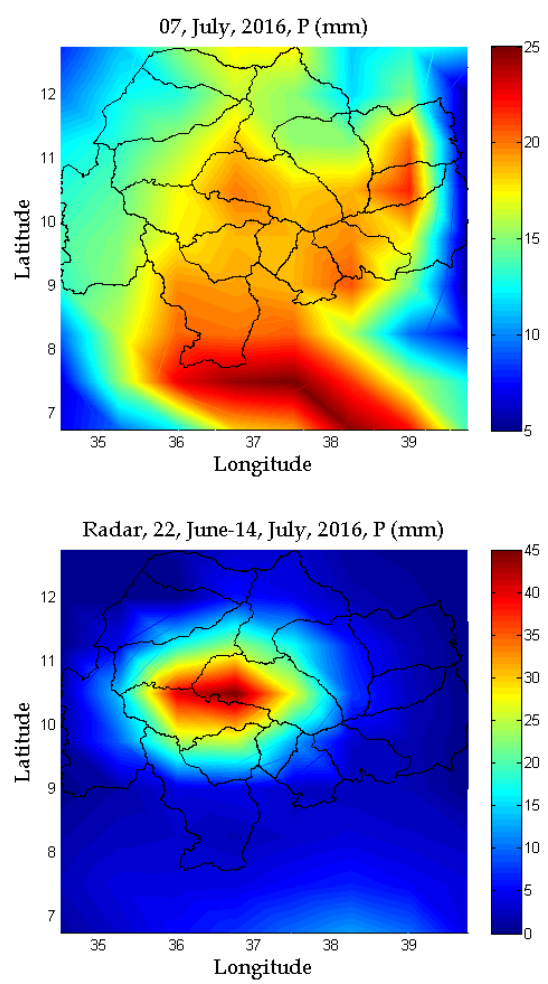

Fig. 8: The comparisons between ECMWF and Z-R relation precipitation data from 22 June 2016 to 14 July 2016.

value of $23 \mathrm{~mm}$ (see the top-left and top-right panel of Fig. 8). As indicated above, in the western parts of the radar, there is no rain observation but it may rain because of ground clutters, the transmitted signal is reflected back to near the radar receiver before reaches the farther targets. The range of rainfall from the radar Z-R relation model is varied from 2-26 $\mathrm{mm}$ with the spatial average value of $16.2 \mathrm{~mm}$, while ECMWF ERA-interim is varied from $5-23 \mathrm{~mm}$ with spatial average value of $15.4 \mathrm{~mm}$. The bias ratio and mean relative error between ECMWF and Z-R relation model were found 0.95 and 0.05 , respectively. The spatial correlation coefficient of rainfall from the radar Z$\mathrm{R}$ relation model and ECMWF was 0.76 . This suggests better relationship between them.

For further investigation, a cross comparison of rainfall from the radar Z-R relation model and ECMWF ERA-interim reanalysis data is also performed (see the bottom-left and bottom-right panel of Fig. 8). The 23 coincident day data from 22 June 2016 to 14 July 2016 is obtained from the radar and ECMWF reanalysis depends on the availability of the radar data. Both the bottom-right and bottom-left panel of Fig. 8 are illustrated using MATLAB software. The range of rainfall from ECMWF ERA-interim is varied from 5-34 mm with spatio temporal average value of $20.01 \mathrm{~mm}$ (see bottom-right panel of Fig. 8). While the radar Z-R relation model is varied from 2.1-36.3 mm with spatio temporal average value of 20.50 $\mathrm{mm}$ (see bottom-left panel of Fig. 8). The average difference between them is $0.49 \mathrm{~mm}$. It has a good performance as we considered a short period of data. In the long year precipitation data, the average difference between gauge and ECMWF was 0.11. Gauge and ECMWF is better agreement than radar Z-
$\mathrm{R}$ relation model and ECMWF. This is suggesting that, the absolute difference of precipitation from the radar Z-R relation and ECMWF is bounded within $49 \%$.

\section{Conclusions And Recommendations}

By analyzing the Z-R relation rainfall data from UBNB radar and $\mathrm{R}$ data from the gauge at different site around UBNB, leads to the following conclusions. The significant difference is observed at Gonder gauge station against the Z-R relation error model from the radar by applying projectile rainfall motion correction and without projectile motion correction. This variation is occurred as a result of high wind speed during rainfall over the region. The daily wind is nearly zero, the error model before and after the application of projectile motion is the same. Projectile rainfall motion correction is essential to obtain accurate and prices of weather radar rainfall data. The likelihood function is a very important method to determine Z-R relation parameters. The average value of rainfall data obtained from Z-R relation model is greater than the gauge direct observation. This difference is occurred due to evaporation, wind direction and the orientation of the gauge in the ground. The availability of gauge stations in Ethiopia are very spares, it could not capture the amount of rainfall variability in a required spatial and temporal resolution. Therefore, an empirical Z-R relation model from the radar is quite useful by considering projectile rainfall motion correction. By applying the application of projectile motion correction, the total error is reduced by $12 \%$. After the application of projectile rainfall motion correction, the ECMWF and Z-R relation model showed good performance. 
From our analysis, the assumption of projectile method is very important for improving the radar data over UBNB and we wish to extend this method for other regions.

\section{REFERENCES}

[1] C. Onyutha and P. Willems, "Spatial and temporal variability of rainfall in the nile basin," Hydrology and Earth System Sciences \& Discussions, vol. 11, pp. 11945-11945, 2014.

[2] L. Worku, "Climate change impact on variability of rainfall intensity in the upper blue nile basin," Proceedings of the International Association of Hydrological Sciences, vol. 366, pp. 135-136, 2015.

[3] K. Stellman, H. Fuelberg, R. Garza, and M. Mullusky, "An examination of radar and rain gauge-derived mean areal precipitation over georgia watersheds," Weather and Forecasting, vol. 16, no. 1, pp. 133-144, 2001.

[4] H. Sharif, F. Ogden, W. Krajewski, and M. Xue, "Statistical analysis of radar rainfall error propagation," Journal of Hydrometeorology, vol. 5, no. 1, pp. 199-212, 2004.

[5] M. Peura, J. Koistinen, and H. Hohti, "Quality information in processing weather radar data for varying user needs," in Proceedings of ERAD, 2006, pp. 563-566.

[6] E. Vivoni, D. Entekhabi, and R. Hoffman, "Error propagation of radar rainfall nowcasting fields through a fully distributed flood forecasting model," Journal of Applied Meteorology and Climatology, vol. 46, no. 6, pp. 932-940, 2007.

[7] C. Collier, "On the propagation of uncertainty in weather radar estimates of rainfall through hydrological models," Meteorological Applications: A journal of forecasting, practical applications, training techniques and modelling, vol. 16, no. 1, pp. 35-40, 2009.

[8] A. Prein, A. Gobiet, M. Suklitsch, H. Truhetz, N. Awan, K. Keuler, and G. Georgievski, "Added value of convection permitting seasonal simulations," Climate Dynamics, vol. 41, no. 9-10, pp. 2655-2677, 2013.

[9] E. Kendon, N. Ban, N. Roberts, H. Fowler, M. Roberts, S. Chan, J. Evans, G. Fosser, and J. Wilkinson, "Do convection-permitting regional climate models improve projections of future precipitation change?" Bulletin of the American Meteorological Society, vol. 98, no. 1, pp. 79-93, 2017.

[10] M. Allam, A. Jain Figueroa, D. McLaughlin, and E. Eltahir, "Estimation of evaporation over the upper b lue $n$ ile basin by combining observations from satellites and river flow gauges," Water Resources Research, vol. 52, no. 2, pp. 644-659, 2016.

[11] M. Birhan, U. Raju, and S. Kenea, "Estimation of rainfall intensity from first observation weather radar reflectivity data over upper blue nile basin, ethiopia," Trans. Sci. Technol., vol. 5, no. 4, pp. 223-232, 2018.

[12] P. Tabary, "The new french operational radar rainfall product. part i: Methodology," Weather and forecasting, vol. 22, no. 3, pp. 393-408, 2007.

[13] U. Germann and J. Joss, "Operational measurement of precipitation in mountainous terrain," in Weather Radar, 2004, pp. 52-77.

[14] M. Winchell, H. Gupta, and S. Sorooshian, "On the simulation of infiltration-and saturation-excess runoff using radar-based rainfall estimates: Effects of algorithm uncertainty and pixel aggregation," Water Resources Research, vol. 34, no. 10, pp. 2655-2670, 1998.

[15] E. Morin, W. Krajewski, D. Goodrich, X. Gao, and S. Sorooshian, "Estimating rainfall intensities from weather radar data: The scaledependency problem," Journal of Hydrometeorology, vol. 4, no. 5, pp. 782-797, 2003.

[16] G. Ciach, W. Krajewski, and G. Villarini, "Product-error-driven uncertainty model for probabilistic quantitative precipitation estimation with nexrad data," Journal of Hydrometeorology, vol. 8, no. 6, pp. 1325-1347, 2007.

[17] P. Mandapaka, W. Krajewski, G. Ciach, G. Villarini, and J. Smith, "Estimation of radar-rainfall error spatial correlation," Advances in Water Resources, vol. 32, no. 7, pp. 1020-1030, 2009.

[18] E. Habib, A. Aduvala, and E. Meselhe, "Analysis of radar-rainfall error characteristics and implications for streamflow simulation uncertainty," Hydrological sciences journal, vol. 53, no. 3, pp. 568-587, 2008.

[19] A. AghaKouchak, E. Habib, and A. Bárdossy, "Modeling radar rainfall estimation uncertainties: Random error model," Journal of Hydrologic Engineering, vol. 15, no. 4, pp. 265-274, 2009.

[20] D. Zhu, D. Peng, and I. Cluckie, "Statistical analysis of error propagation from radar rainfall to hydrological models," Hydrology and Earth System Sciences, vol. 17, no. 4, pp. 1445-1453, 2013.
[21] F. Gekat, P. Meischner, K. Friedrich, M. Hagen, J. Koistinen, D. Michelson, and A. Huuskonen, "The state of weather radar operations, networks and products," in Weather Radar, 2004, pp. 1-51.

[22] J. Bech, U. Gjertsen, and G. Haase, "Modelling weather radar beam propagation and topographical blockage at northern high latitudes," Quarterly Journal of the Royal Meteorological Society: A journal of the atmospheric sciences, applied meteorology and physical oceanography, vol. 133, no. 626, pp. 1191-1204, 2007.

[23] D. Bebbington, S. Rae, J. Bech, B. Codina, and M. Picanyol, "Modelling of weather radar echoes from anomalous propagation using a hybrid parabolic equation method and nwp model data," Natural Hazards and Earth System Science, vol. 7, no. 3, pp. 391-398, 2007.

[24] D. Conway, "The climate and hydrology of the upper blue nile river," Geographical Journal, vol. 166, no. 1, pp. 49-62, 2000.

[25] W. Abera, G. Formetta, L. Brocca, and R. Rigon, "Water budget modelling of the upper blue nile basin using the jgrass-newage model system and satellite data," Atmospheric Research, pp. 178-179, 2016.

[26] D. Conway, "A water balance model of the upper blue nile in ethiopia," Hydrological sciences journal, vol. 42, no. 2, pp. 265-286, 1997.

[27] E. Morin, W. Krajewski, D. Goodrich, X. Gao, and S. Sorooshian, "Estimating rainfall intensities from weather radar data: The scaledependency problem," Journal of Hydrometeorology, vol. 4, no. 5, pp. 782-797, 2003.

[28] U. Germann, M. Berenguer, D. Sempere-Torres, and G. Salvade, "Ensemble radar precipitation estimation-a new topic on the radar horizon," in Proceedings 4th European Conference on Radar in Meteorology and Hydrology, 2006, pp. 559-562.

[29] E. Saltikoff, P. Lopez, A. Taskinen, and S. Pulkkinen, "Comparison of quantitative snowfall estimates from weather radar, rain gauges and a numerical weather prediction model," Boreal Environment Research, vol. 20, pp. 667-678, 2015.

[30] S. Sorooshian, V. Gupta, and J. Fulton, "Evaluation of maximum likelihood parameter estimation techniques for conceptual rainfall-runoff models: Influence of calibration data variability and length on model credibility," Water Resources Research, vol. 19, no. 1, pp. 251-259, 1983.

[31] S. Brandt, Data Analysis: Statistical and Computational Methods for Scientists and Engineers. Springer International Publishing, 2014.

[32] M. Montopoli and F. Marzano, "Maximum-likelihood retrieval of modeled convective rainfall patterns from midlatitude c-band weather radar data," IEEE transactions on geoscience and remote sensing, vol. 45, no. 7, pp. 2403-2416, 2007.

[33] J. Haddad, M. Nimah, and N. Farajallah, "Modeling annual rainfall: a robust maximum likelihood approach," Environmetrics: The official journal of the International Environmetrics Society, vol. 18, no. 1, pp. 101-105, 2007. 